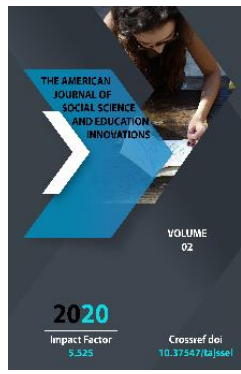

\title{
Developing The Concept Of Multimedia As Educational Aid In Teaching English Language At Elementary Schools
}

\author{
Valiyeva Shahlo Akmalovna \\ Lecturer Of The Department Of English Language And Literature Of The Faculty Of World \\ Languages, Namangan State University, Uzbekistan
}

Copyright: Original content from this work may be used under the terms of the creative commons attributes 4.0 licence.

\section{ABSTRACT}

This article discusses developing the concept of multimedia as educational aid in teaching English as a foreign language and the application of electronic educational textbooks at elementary schools.

\section{KEYWORDS}

Multimedia technologies, multimedia textbook, computer technologies, teaching English, elementary school.

\section{INTRODUCTION}

The implementation of the priority tasks in educational system of Uzbekistan requires modernization of the learning process and a widespread computerization of all educational levels. Overcoming these problems is associated with the need to develop information and educational environments that allow: a) To form the competencies necessary for a person living in a dynamically changing world;

b) To ensure equal learning conditions for all participants in the educational process;

c) To create an interactive educational environment for any categories of users and in the system of any training structure. 


\section{MATERIALS AND METHODS}

The advantages of using multimedia technologies in the educational process have been proven in many scientific works and confirmed by teaching practice such as the great potential of multimedia content for the development of creative imagination, activation of the intellectual activity of a person, visual presentation of educational material and the ability to simulate real phenomena of the surrounding world. According to foreign research in the field of cognitive psychology, the combination of video, audio and text in the learning process allows:

a) To build the interaction of verbal and figurative models of knowledge;

b) To eliminate the overload of the cognitive system of pupils;

c) To use several channels of information processing, complementing each other;

d) To carry out an individual approach to training.

The authors note the importance of the emotional component in the process of perceiving multimedia texts, as it provides the formation of motivation for learning, to make understanding and memorization as easy as possible, to make it active, involving in the learning process the capabilities of the human brain different from that of a conventional textbook. The multimedia text book "Kids'English" was developed for pupils of first, second, third and fourth grades of secondary schools by authors S.Khan, L.Djurayev, K Inagamova. Its theoretical basis was:
1) Didactic requirements for educational literature for elementary school;

2) Bibliological requirements for multimedia educational content;

3) Works in the field of technology for creating electronic teaching aids;

4) State standards for publishing.

The tutorial was based on the following provisions:

1) Since the physiological characteristics of the development of children 7-10 years old require strict time restrictions on working with a computer, it is more expedient to use multimedia content in elementary school as an attachment to the main educational material by teachers;

2) The electronic application is easy to use at lessons;

3) The multimedia application should be aimed at consolidating knowledge and skills, the formation of practical skills, mastering the forms and methods of cognition;

The purpose of the textbook "Kid's English" determined the formulation of educational, developmental and teaching tasks of the textbook.

Educational tasks:

1) To form a system of cognitive interests in younger pupils;

2) Introduce them to the traditions of national and world culture;

3) Stimulate the development of creativity;

4) To develop skills of independent work and initiative.

Developmental tasks:

1) To promote the development of interest in learning English; 
2) Develop logical, problematic, associative thinking in younger pupils;

3) Help broaden their horizons.

Learning tasks:

1) Expand the linguistic horizons of younger pupils;

2) Contribute to the effective assimilation of the phonetics of the English language;

3) Promote the formation and development of skills related to the pronunciation of the sounds of the English language;

4) Form a basic vocabulary on which further learning of the English language will be based;

5) Develop the ability to combine the operations of reading and speaking.

The multimedia text book “Kids'English" provides:

1) Alphabetic characters form the basis of the teaching material, since they provide the development of reading skills in the native and foreign languages, contribute to the development of thinking and imagination. By means of alphabetic characters, information about English letters, the peculiarities of their pronunciation, the content of game training tasks are transmitted. Fragments of the text are composed in accordance with the peculiarities of the age category of 7-9 years old and are distinguished by concreteness and conciseness;

2) Multimedia (video about letters, with English words and corresponding pictures) provide the dynamics of the perception of the teaching material, contribute to the memorization of English vocabulary based on the combination of words and images;

3) Audio recordings ("sounding" English words in stories about letters and in play educational tasks, children's English songs) contribute to the development of listening comprehension, the formation of the ability to perceive English speech and memorize English words based on repetition after audio recording.

\section{CONCLUSION}

As conclusion, we can say that the aim of creating the concept of a multimedia textbook prove that the developers of such educational materials should be not only teachers, but also publishers, IT specialists and web designers. As multimedia textbook provides the formation of motivation for learning including to make understanding and memorization as easy as possible and involving in the learning process actively.

\section{REFERENCES}

1. S.Khan, L.Djurayev, $\mathrm{K}$ Inagamova (2015), Kid's English for 1st grades", Tashkent, Uzbekistan publishing house

2. S.Khan, L.Djurayev, K Inagamova, O.Mahsudova (2016), Kid's English for 2st grades", Tashkent, Uzbekistan publishing house

3. Muhammadiyeva, H., Mahkamova, D., Valiyeva, S., \& Tojiboyev, I. (2020). The role of critical thinking in developing speaking skills. International Journal on Integrated Education, 3(1), 62-64.

4. Sarimsakova, D. (2017). Station Rotation. English Teaching Professional, 109.

5. Sarimsakova, D. M. (2020). SOCIOLINGUISTIC COMPETENCE AND COMMON REFERENCE LEVELS OF THE CEFR. In МИРОВАЯ ЭКОНОМИКА. 
The American Journal of Social Science and Education Innovations (ISSN - 2689-100x)

Published: December 28, 2020 | Pages: 219-222

Doi: https://doi.org/10.37547/tajssei/Volumeo2Issue12-39

2020: $5 \cdot 525$

ПРОБЛЕМЫ, ПЕРСПЕКТИВЫ,
ИННОВАЦИИ (pp. 4-6).
6. https://kidsenglish.ucoz.com/

OCLC - 1121105668

ИННОВАЦИИ (рр. 4-6).

6. https://kidsenglish.ucoz.com/ 